\title{
Food Companies' Calorie-Reduction Pledges to Improve U.S. Diet
}

\author{
Meghan M. Slining, PhD, Shu Wen Ng, PhD, and Barry M. Popkin, PhD \\ Department of Nutrition, University of North Carolina at Chapel Hill, Chapel Hill, North Carolina
}

\begin{abstract}
Heretofore, corporate voluntary pledges to improve the health of Americans have been linked neither to explicit measurable commitments nor to a framework for an independent evaluation. The Healthy Weight Commitment Foundation (HWCF), whose members include 16 of the nation's leading consumer packaged goods food and beverage manufacturers, voluntarily pledged to collectively remove 1 trillion calories from their products by 2012 (against a 2007 baseline), and 1.5 trillion calories by 2015 . The pledge is designed to reduce the calorie gap commensurate with the HWCF companies' role in the U.S. diet. To date, no system exists for documenting the nutritional and public health impacts of industry-led changes in the food supply on individual diets.

The current study represents a unique opportunity to understand how the consumer packaged goods food and beverage sector is changing and how these changes are associated with changes in the American diet. It presents data on national caloric sales from this sector, purchases of these goods by various subpopulations, and methods linking these to individual intakes of Americans. Findings show that HWCF companies accounted for approximately $25 \%$ of calories consumed in the U.S. in 2007 and that the 1.5 trillion-calorie pledge (about 14 calories/day/capita) accounts for $0.8 \%$ of the calories sold across all consumer packaged goods food and beverage brands in 2007. The authors hope that this evaluation will continue to create models and methods for demonstrating the effects of changes in the food supply on individual diets, particularly among those from vulnerable subpopulations.
\end{abstract}

\section{Introduction}

Reducing overweight and related consequences is a national priority. The important role of food companies in improving the food supply is not disputed. ${ }^{1-3}$ Recently, pledges from consumer packaged goods food and beverage companies to reduce calories sold have created a need to understand how changes in this food sector affect U.S. diets.

The current U.S. food monitoring system does not adequately track brand-specific changes in food composition or sales to understand their unique impact. Presented here are baseline data and methods to monitor one set of pledges from these companies. Food and beverage companies globally have made numerous voluntary pledges and commitments to

\footnotetext{
(C) 2012 American Journal of Preventive Medicine. Published by Elsevier Inc. All rights reserved.

Address correspondence to: Barry M. Popkin, PhD, Carolina Population Center, University of North Carolina, 123 W. Franklin St., Chapel Hill NC 27516-3997. popkin@unc.edu.

No financial disclosures were reported by the authors of this paper.

Publisher's Disclaimer: This is a PDF file of an unedited manuscript that has been accepted for publication. As a service to our customers we are providing this early version of the manuscript. The manuscript will undergo copyediting, typesetting, and review of the resulting proof before it is published in its final citable form. Please note that during the production process errors may be discovered which could affect the content, and all legal disclaimers that apply to the journal pertain.
} 
reformulate products, improve diet quality, and improve marketing practices targeting children. ${ }^{4-8}$ Although scholars have attempted to delineate whether and how such voluntary efforts produce positive outcomes, these evaluations have not tracked actual changes in diets. $^{9-13}$

In this context, the voluntary pledge from the Healthy Weight Commitment Foundation (HWCF) is unique. The HWCF is broad, including initiatives in schools, worksites, and the marketplace. In the marketplace, HWCF's focus is on "reducing or controlling calories while preserving or enhancing the overall nutrition of healthier product options." 14 Using 2007 as a baseline year, 16 major HWCF food-manufacturing companies pledged to collectively remove 1.5 trillion calories from the marketplace by 2015 , with an interim goal of 1 trillion calories by $2012 .{ }^{15}$ This target was based on the estimated HWCF company share (25\% of total energy consumed in the U.S.) of the published estimates of the calorie gap needed to prevent excessive weight gain. ${ }^{16-18}$ The Robert Wood Johnson Foundation (RWJF) committed to fund an independent evaluation of the HWCF marketplace pledge focused on the calorie reduction targets as well as the impact on U.S. child diets.

\section{The Healthy Weight Commitment Foundation Marketplace Pledge}

Sixteen companies pledged to reduce calories sold in the U.S.: Bumble Bee Foods, LLC; Campbell Soup Company; ConAgra Foods; General Mills, Inc.; Kellogg Company; Kraft Foods, Inc.; Mars, Incorporated; McCormick \& Company, Inc.; Nestlé USA; PepsiCo, Inc.; Post Foods/Ralston Foods, LLC; Sara Lee Corporation; The Coca-Cola Company; The Hershey Company; The J.M. Smucker Company; and Unilever. Their pledge includes all of their companies' food and beverage products with a barcode or Universal Product Code (UPC) sold through vending machines and in stores (grocery/food stores, drug stores, mass merchandisers, and convenience stores). Excluded products are listed in Appendix A (available online at www.ajpmonline.org).

\section{Evaluation Overview}

This paper provides the baselinebenchmarks on which to evaluate the HWCF marketplace efforts. To track how marketplace changes relate to individual diets, the evaluation utilizes existing public and commercial data sets, each with their own strengths and limitations (see Appendix B, available online at www.ajpmonline.org, for a comparison of these sources). ${ }^{19}$ Consequently, the evaluation is comprised of three distinct studies designed to answer the following questions:

Study 1: Did the HWCF companies reduce their total calories sold by 1 trillion between 2007 and 2012, and by 1.5 trillion between 2007 and 2015, and what food categories were sources of the caloric changes?

Study 2: What are the changes in average daily calories purchased and top sources of calories purchased from HWCF, non-HWCF, and private label products by U.S. households with children aged 2-18 years between 2007 and 2012 (and between 2007 and 2015)? Are the changes different for lower-income and race/ethnicity subpopulations at greatest risk for childhood obesity (African Americans and Hispanics)?

Study 3: What are the changes in average daily calories consumed and top sources of calories consumed from HWCF, non-HWCF, and private label products by U.S. children aged 2-18 years between 2007 and 2012 (and between 2007 and 2015)? Are the changes different for lower-income and race/ethnicity subpopulations at greatest risk for childhood obesity (African Americans and Hispanics)? 
To ensure the highest scientific integrity and transparency, RWJF and the University of North Carolina Food Research Program (UNCFRP) established an independent Evaluation Advisory Committee of eminent scholars to provide scientific review and advice. ${ }^{20} \mathrm{~A}$ critical dimension of all work by the UNCFRP and its collaborating groups, the committee, and RWJF, is full transparency in decisions regarding data acquisition, analysis, and interpretation for all three studies.

\section{Data Sources}

For transparency and reproducibility of findings, the proposed evaluation does not utilize proprietary company data. Instead, the authors rely on existing data available either at no cost or for purchase by any research group. ${ }^{19}$ To the extent legally permitted, the authors plan to make select data created through the evaluation publically available.

\section{Commercial Data Sources}

Nielsen Scantrack (consumer packaged goods sales data)—Nielsen Scantrack data from 2007, 2012 and 2015 will be used to track sales of HWCF products. These storebased scanner data provide records of weekly price, dollar sales, and units sold of all UPC transactions at participating grocery, drug, mass merchandiser, and convenience stores. These represent aggregate sales and are not linked to individuals. ${ }^{19,21}$ Scantrack is a stratified systematic probability sample designed to measure consumer sales across 52 major markets and can be projected nationwide for the stores captured within its sample. ${ }^{19,21}$ Sampling limitations are offset by combining these data with the Nielsen Homescan data discussed below.

Nielsen Homescan (consumer packaged goods purchase data)-Nielsen Homescan data from 2000 through 2015 will be used for longitudinal analyses of purchases of HWCF products. Homescan contains detailed UPC-level information about household food purchases brought into the home and contains all UPC transactions from all outlet channels, including grocery, drug, mass-merchandise, club, supercenter, and convenience stores. ${ }^{19}$ The data are collected daily by providing scanning equipment to a sample of over 50,000 households each year from 2000 to $2015 .^{22-24}$

Nutrition Facts Panel consumer packaged goods nutrition data-These data are the nutrition data found on food and beverage labels. Label information from each UPC (all macronutrients, other vitamins and minerals, ingredients) ${ }^{25}$ is obtained from several commercial sources, the primary source being the Gladson Nutrition Database.

\section{Public Data Sources}

What We Eat in America (dietary intake data)—These data come from the dietary intake interview component of the National Health and Nutrition Examination Survey (NHANES) and are released in 2-year survey periods. The 2007/2008 data will be used for the baseline, with 2011/2012 and 2015/2016 being the comparison time periods. ${ }^{26}$

Food and Nutrient Database for Dietary Studies (food composition data)-This database, which is the source of nutrient data for the NHANES interview component discussed above, is based on nutrient values in the U.S. Department of Agriculture (USDA) National Nutrient Database for Standard Reference. ${ }^{27}$ The baseline assessment presented here uses Version 4.1 of this database, which is based on Standard Reference Release 22 (corresponding to foods and beverages reported in NHANES What We Eat in America $2007 / 2008^{28}$ ). 


\section{Methods}

Study 1 is the official evaluation of the HWCF pledge on sales from consumer packaged goods foods and beverages. Studies 2 and 3 examine how these changes are associated with the diets of U.S. individuals and households with a focus on the lower-income and race/ ethnicity subpopulations at greatest risk for childhood obesity (African Americans and Hispanics).

\section{Baseline Total Caloric Sales from Consumer Packaged Goods Products (Study 1)}

To determinetotal caloric sales, data fr om nutrition facts panels were linked with each Scantrack UPC (accounting for $97 \%$ of the volume sales in the 2007 baseline period (Appendix C, available online at www.ajpmonline.org). Nielsen-developed mutually exclusive food (41) and beverage (21) categories were utilized for examining key calorie sources (Appendix D, available online at www.ajpmonline.org). These categories reflect product placement in stores and are not nutritionally based. After completion of the crosswalk (described below) these categories will be revised.

To distinguish the proportion of calories from HWCF companies, non-HWCF companies and private label, foods and beverages have been classified according to brands and product lines. Evaluation-related HWCF products were verified by the HWCF companies. A simple aggregate of Scantrack calories sold underestimates national sales because the Scantrack sample does not include Walmart, club stores and smaller stores that represent a substantial proportion of sales. ${ }^{19}$ Using Homescan, food category brand- or outlet-specific proportions of purchases from stores that did not participate in Scantrack were used to adjust Scantrack to more fully capture calories sold (Appendix E, available online at www.ajpmonline.org). These adjusted Scantrack 2007 data provide the baseline measure for total caloric shares of HWCF products sold compared to non-HWCF and private label products.

\section{Baseline Average Daily Calories Purchased from Consumer Packaged Goods Products by U.S. Households with Children Aged 2-18 Years (Study 2)}

Using the same approach used in Study 1 for linking the Homescan purchase data with NFP data, 95\% of the volume purchases in Homescan 2007 are accounted for (Appendix C, available online at www.ajpmonline.org). Average daily total calories purchased, the top sources of calories purchased, and the proportion of calories from HWCF companies, nonHWCF companies, and private label brands were derived using the same approach as that in Study 1. Since Homescan data are at the household level, the number of calories from children or adolescents within households is not easily estimated. Therefore, in order to translate Homescan purchases from the household to individual level, regression-based adjustments were conducted to estimate the calories purchased for each child aged 2-18 years from various subpopulations of interest using demographic information on household composition, race/ethnicity of the household head and household income.

\section{Baseline Average Daily Calories Reported Consumed from Stores and Vending Machines by U.S. Children Aged 2-18 Years (Study 3)}

To measure the average daily calories consumed and the sources of these calories by U.S. children and adolescents at baseline, the mean intake of total energy reported in two 24-hour dietary recalls from the NHANES What We Eat in America 2007/2008 was calculated. Because the HWCF pledge only includes products sold through vending machines and in stores (grocery, drug, mass merchandisers and convenience stores), these analyses are limited to intake reported as obtained in stores and through vending machines. To identify top sources of calories consumed, all foods and beverages were classified into mutually 
exclusive food (40) and beverage (15) groups (Appendix F, available online at www.ajpmonline.org).

The data from this portion of NHANES do not distinguish manufacturer or brand of all foods and beverages. Further, because the USDA does not conduct comprehensive updates of the food composition data annually, it is unlikely that the nutrient data from the Food and Nutrition Database for Dietary Studies will capture the ongoing reformulations of products linked with the HWCF efforts. Therefore, to distinguish the proportion of calories from HWCF companies and attach up-to-date commercial nutrient information to NHANES What We Eat In America dietary data, a "crosswalk" is being developed between the public consumption and commercial purchase and nutrient data sources.

The crosswalk will connect each of the USDA food codes that appears in the NHANES What We Eat in America dietary intake survey (reported to have been obtained from stores or vending machines) to corresponding UPCs representing food and beverage products that appear in the Homescan data during the equivalent time period (Figure 1). Loose (unpackaged) fruits, vegetable items, cut-to-order meats (items without UPCs), and homemade recipe items that do not appear in the commercial data sources will not be linked. These items represent less than $6 \%$ of total consumption reported by U.S. children and adolescents in this NHANES 2007/2008 survey.

The crosswalk achieves three important results. First, it allows application of nutrient information from the commercial data to NHANES What We Eat in America survey data. A composite nutrient profile based on the weighted average of volume sales for all appropriate UPC matches is created for each USDA food code. The aggregate of all nutrient profiles is the UNCFRP Nutrient Database. Second, the crosswalk allows determination of the proportion of calories reported as consumed by children and adolescents in this NHANES survey that are attributable to HWCF, non-HWCF and private label products. Finally, completion of the crosswalk facilitates comparisons across public and commercial data sources as the same food-grouping system can be applied to all data sources.

\section{Results}

\section{Baseline Total Caloric Sales from Consumer Packaged Goods Products (Study 1)}

Figure 2 shows the total caloric sales from consumer packaged goods by aggregate HWCF, non-HWCF, and private label brands in 2007 using unadjusted Scantrack data compared to adjusted Scantrack data. Despite differences in the absolute number of calories, the relative caloric shares are comparable. Based on the adjusted Scantrack values, of the 186.2 trillion calories sold from packaged foods and beverages in 2007, a total of 67.3 trillion calories (or $36.2 \%$ ) were from the $16 \mathrm{HWCF}$ companies.

Non-HWCF brands account for $38.9 \%$, and private label products account for the remaining $24.9 \%$. Given that $69.9 \%$ of calories in $2007 / 2008$ came from stores and vending machines, HWCF companies accounted for about $25 \%$ of all calories consumed in the U.S. Another way to consider this is the 1.5 trillion-calorie reduction private label edge (about 13-14 calories/day for the average consumer) accounts for $2.2 \%$ of the calories that the HWCF companies sold in 2007 , and $0.8 \%$ of the calories sold across all consumer packaged goods food and beverage brands in 2007.

Appendix G (available online at www.ajpmonline.org) presents results (adjusted Scantrack) for the full list of food and beverage categories ranked by contribution to total calories sold in 2007 as well as caloric sales of consumer packaged goods by food and beverage categories and the proportion of calories attributable to HWCF products within each food 
category. Top sources of calories (per day per capita) from consumer packaged goods food categories include shelf-stable snacks ( 105 calories), ready-to-eat breads ( 92 calories), candy and gum ( 85 calories), ready-to-eat cereals and granola ( 55 calories), cheese (54 calories), refrigerated processed meats ( 51 calories), and cookies (48 calories). HWCF products account for $>50 \%$ of calories from these top food categories: shelf-stable snacks (59\%), candy and gum (64\%), and ready-to-eat cereals and granola (74\%). Among beverage groups, the top sources of daily calories per capita for 2007 include fresh plain milk (81 calories), carbonated soft drinks ( 71 calories), shelf-stable fruit and vegetable drinks and juice (54 calories), and alcohol (54 calories). HWCF caloric shares in the beverage groups were the most pronounced for water (98\%), carbonated soft drinks (58\%) and beverage powders and concentrates $(68 \%)$.

\section{Baseline Average Daily Calories Purchased from Consumer Packaged Goods Products by U.S. Households with Children Aged 2-18 Years (Study 2)}

To evaluate the relationship between HWCF company efforts and purchases from consumer packaged goods products by U.S. households with children aged 2-18 years, a pre-post longitudinal analysis that allows for control of an array of economic, demographic and related conditions that affect household food purchases was used. Table 1 presents baseline results adjusted only for household age-gender composition, household income, and race/ ethnicity of the head of the household to provide a crude measure of marginal intake of calories purchased per child. In 2007, the average daily total calories purchased for the average child aged 2-18 years is 1119 calories, of which $38.5 \%$ (432 calories) are from HWCF products, $31 \%$ (347 calories) are from non-HWCF products, and 30.4\% (341 calories) are from private label products.

Appendix H (available online at www.ajpmonline.org) presents regression-adjusted calories purchased for an average child aged 2-18 years for each food and beverage category as well as the proportion of calories attributable to HWCF products within each category. Among food groups, the top sources of calories per day per child include shelf-stable snacks (75 calories), ready-to-eat cereals and granola (64 calories), ready-to-eat breads (55 calories), candy and gum (50 calories), cheese (36 calories), cookies (31 calories), and refrigerated processed meats ( 31 calories). HWCF products account for more than $50 \%$ of the calories from these top food groups: shelf-stable snacks (58\%), ready-to-eat cereals and granola (74\%), candy and gum (67\%), and cookies (53\%). Among beverage groups, the top sources of average daily calories per child include fresh plain milk (68 calories), shelf-stable fruit and vegetable drinks and juices ( 35 calories), and carbonated soft drinks (29 calories). HWCF caloric shares in these groups were the most pronounced for carbonated soft drinks $(57 \%)$, beverage powders and concentrates $(74 \%)$, and waters $(98 \%)$.

\section{Baseline Average Daily Calories Reported Consumed from Stores and Vending Machines by U.S. Children Aged 2-18 Years (Study 3)}

A portion of the crosswalk is complete. Preliminary results are presented and discussed in Appendix I (available online at www.ajpmonline.org). Table 2 presents the calories reported as consumed in NHANES What We Eat in America 2007/2008 by children aged 2-18 years from foods and beverages obtained through vending machines and stores only, applying Food and Nutrition Database for Dietary Studies 4.1. This age group reported consuming 1275 calories from stores and vending machines, representing approximately $68.1 \%$ of total daily energy reported. Younger children reported consuming fewer calories than older children, and African Americans and Hispanics reported consuming fewer calories than whites. These subpopulation differences are consistent with what was found in Homescan 2007 (Table 1). 
The top food and beverage sources of calories reported as consumed by children and adolescents in NHANES What We Eat in America 2007/2008 (applying Food and Nutrition Database for Dietary Studies data) are presented in Appendix J (available online at www.ajpmonline.org). The top food sources of calories (per day per capita) from stores and vending machines include grain-based desserts (134 calories), savory snacks (120 calories), pasta and pasta dishes (111 calories), breads (105 calories) and ready-to-eat cereals (83 calories). The top beverage sources of calories (per day per capita) from stores and vending machines include fluid milk (143 calories), sugar-sweetened beverages (102 calories) and fruit juice (56 calories). After completion of the crosswalk, these analyses will be updated (applying the UNCFRP Nutrient Database) and the role of HWCF companies will be determined for all food and beverage categories.

\section{Comparison of Baseline Results Across Studies 1-3}

Table 3 provides a summary of results across data sources. As expected, the adjusted Scantrack estimates are higher than Homescan and NHANES What We Eat in America estimates due to differences in possible sources of measurement error across data sources (Appendix B, available online at www.ajpmonline.org). While results from the data sources differ in magnitude, findings across subpopulations are remarkably consistent. The adjusted Scantrack 2007 estimates show that participating HWCF companies produced about $36.2 \%$ of consumer packaged goods calories in 2007. Data from NHANES What We Eat in America 2007/2008 indicate that calories from stores (primarily consumer packaged goods) comprise $68.1 \%$ of total calories consumed by those aged 2-18 years. Taken together, these results suggest that the $16 \mathrm{HWCF}$ companies account for about $25 \%$ of total calories reported consumed by children and adolescents.

\section{Discussion}

The HWCF pledge is one of the most visible and important pledges made by food and beverage companies and was designed to directly improve the food supply for American children and their families. The evaluation of the HWCF pledge and its relationship with U.S. child diet required the creation of a system that links sales and purchases of consumer packaged goods foods and beverages to individual dietary intake. This effort presents unique opportunities and challenges for documenting the public health effects of concerted industry-led changes in the food supply.

The authors have made substantial progress in developing a scientifically sound evaluation design and establishing the personnel and database infrastructure to complete a methodologically rigorous evaluation of the HWCF calorie-reduction targets and their association with the diets of U.S. children and adolescents. ${ }^{11,29-34}$ This paper provides the baseline benchmarks on which to evaluate the HWCF marketplace efforts. The following sections describe additional analyses and analytic issues relevant to the evaluations of HWCF efforts on sales, purchases and diet between 2007 and the target years.

\section{Ability to Detect Caloric Changes}

Power calculations were conducted to assess the detectable level of caloric change given the sample sizes in Homescan and NHANES What We Eat in America (Appendix K,available online at www.ajpmonline.org). Power calculations using Homescan 2005-2007 show capacity to detect a difference of $\geq 56$ calories purchased per day per household (or 14 calories per day per capita) between the baseline/pre-pledge period and the post-pledge period (Appendix L, available online at www.ajpmonline.org). Power calculations using NHANES What We Eat in America 2007/2008 data show capacity to detect a difference of $\geq 113$ calories per day per capita and $\geq 83$ calories per day per child between the baseline/pre- 
pledge period and the post-pledge period (Appendix M, available online at www.ajpmonline.org).

\section{Additional Analyses to Be Included in 2012 and 2015 Evaluations}

Study 1: Adjusting for changes in volume of market shares over time-Because the recent global food crisis and economic decline have affected food purchase patterns, observed increases or decreases in sales could be unrelated to HWCF behavior. To account for these factors, HWCF caloric shares will be standardized within food and beverage categories (using the 2007 volume sales as the base) to evaluate how HWCF changes are associated with total calories sold in 2007, 2012 and 2015.

Study 2: Longitudinal pre-post design-Even if the HWCF companies meet their marketplace pledge, substitutions to calories purchased from non-HWCF and private label products may result in no or little change in overall calories purchased. Such factors as real income and price changes, shifts in regulations, taxation, and other exogenous influences affect food-purchasing patterns over time. During the HWCF evaluation period, these include global and domestic food price changes (early 2007-December 2008) as well as the Great Recession (December 2007-June 2009) and its aftermath, both of which affected food prices and income differentially.

It is important to take these into account when estimating the association between the HWCF pledge and purchases. For the 2012 evaluation, a model will be fit with 8 years (2000-2007) of pre-pledge and 5 years (2008-2012) of post-pledge food purchase data, controlling for market-level food prices, household characteristics, including income, employment, and other key changes that are associated with household food purchases (calories from each food group) as well as the total set of purchases. Aggregate changes in calories purchased from HWCF, non-HWCF, and private label brands will also be compared.

Some factors that may have occurred will not be accounted for such as shifts in marketing practices of food manufacturers and retailers, changes in food environments and accessibility, and changes in away-from-home eating options, except by assessing overall calorie changes in food sales or purchases and consumption. Similar analyses will be repeated for the 2015 evaluation using 8 years (2008-2015) of post-pledge food purchase data. Appendixes $\mathrm{N}$ and $\mathrm{O}$ (available online at www.ajpmonline.org) describe the longitudinal analysis and variables to be used to test the association between the HWCF pledge and calorie purchases in aggregate and by select income-race-ethnicity subpopulations.

Study 3: Adjusting for usual intake-While shifts in population means have the potential to be small, the effects of the HWCF pledge may be larger among those children and adolescents who consume the most calories (the top 75th or 90th percentiles of the distribution). Using the National Cancer Institute method to estimate the usual intake distribution, ${ }^{35}$ changes in calories consumed by those in the 75th or 90 th percentiles of the distribution, at baseline (2007/2008), 2011/2012, and 2015/2016, will be compared.

Study 3: Examination of total diet-Concurrent changes by the away-from-home food sector (e.g., quick and full-serve restaurants), which represents $30.1 \%$ of calories reported by children and adolescents in NHANES What We Eat in America 2007/2008 might offset or enhance efforts by food manufacturers. Using NHANES What We Eat in America data changes in the away-from-home sector over the corresponding time periods and changes by HWCF companies in the context of the total diet will be examined. 


\section{Limitations}

Due to the complex nature of this evaluation effort and the availability of data, there are important limitations. Foremost are the quality of the Nutrition Facts Panel data and the timeliness of commercial Nutrition Facts Panel databases. The USDA is conducting a detailed, well-sampled full nutrient analysis of the top contributors to sodium in the U.S. and comparing this with the Nutrition Facts Panel on each product to allow assessment of the quality of the Nutrition Facts Panel data for selected consumer packaged goods. The authors are developing methods to evaluate the timeliness of the Gladson Nutrition Facts Panel data updates. The $20 \%$ labeling measurement allowance between what is on the Nutrition Facts Panel and what is found during enforcement analyses ${ }^{25}$ and legal reporting rules reduce the precision of Nutrition Facts Panel data.

Data from the NHANES What We Eat in America survey captures intake of foods and beverages in the as-consumed form. In contrast, the commercial data track sales of aspurchased foods and beverages. To translate items from the as-purchased to the asconsumed form, USDA information on retention and yield factors is being incorporated. ${ }^{28,36}$ However, as it is not possible to account for the various ways in which households may prepare foods, a precise conversion is challenging. Additionally if food waste trends vary over time, particularly linked with the great recession, biases in comparisons of food purchase and dietary intake results will exist. ${ }^{37}$

\section{Conclusion}

The HWCF pledge is a visible, important instance of industry self-regulation to reduce obesity. It is designed to directly improve the food supply for American children and their families. The UNCFRP system established to monitor the nutritional impact of the consumer packaged goods companies represents a major step forward in understanding the U.S. food supply. The developing monitoring system and proposed analyses will improve understanding of how changes in the food supply affect the diets of U.S. children and adolescents.

\section{Supplementary Material}

Refer to Web version on PubMed Central for supplementary material.

\section{Acknowledgments}

The work presented in this paper was supported by funds from RWJF for the Healthy Weight Commitment Foundation Evaluation project (Grant 67506 and 68793). The authors thank team members Izabela Annis, Phil Bardsley, Dan Blanchette, and Donna Miles for exceptional data management and programming support; Lauren Butler and Emily Ford Yoon for excellent research assistance; Peggy Rupert for project management and editorial support; and Frances L. Dancy for superb administrative assistance. The authors also thank and recognize RWJF staff members Tracy Orleans, James Marks, and Elaine Arkin for their extensive advice and guidance during the development of the methods for this evaluation, along with several members of our Evaluation Advisory Committee: Steve Gortmaker (co-chair), Frank Chaloupka, Lisa Powell, Jennifer Seymour, Anna-Maria Siega-Riz, Mary Story, Laurian Unnevehr, and Y. Claire Wang. Lastly, the authors thank the HWCF for their comments and critique.

\section{References}

1. Swinburn BA, Sacks G, Hall KD, et al. The global obesity pandemic: shaped by global drivers and local environments. Lancet. 2011; 378(9793):804-14. [PubMed: 21872749]

2. Scarborough P, Burg MR, Foster C, et al. Increased energy intake entirely accounts for increase in body weight in women but not in men in the UK between 1986 and 2000. Br J Nutr. 2011; 105(9): 1399-404. [PubMed: 21205425] 
3. Swinburn B, Sacks G, Ravussin E. Increased food energy supply is more than sufficient to explain the U.S epidemic of obesity. Am J Clin Nutr. 2009; 90(6):1453-6. [PubMed: 19828708]

4. Hawkes C, Harris JL. An analysis of the content of food industry pledges on marketing to children. Public Health Nutr. 2011; 14(8):1403-14. [PubMed: 21718588]

5. International Food and Beverage Alliance. Commitment to support the WHO's 2004 Global Strategy on Diet, Physical Activity and Health. 2008. www.ifballiance.org/our-commitments.html

6. Children's Food and Beverage Advertising Initiative. 2007. www.bbb.org/us/childrens-food-andbeverage-advertising-initiative/

7. EU platform for action on diet physical activity and health. 2005. ec.europa.eu/health/ nutrition_physical_activity/platform/index_en.htm

8. William J. Clinton Foundation. Alliance for a Healthier Generation-Clinton Foundation and American Heart Association-and industry leaders set healthy school beverage guidelines for US schools. 2006

9. Austin JE. Strategic collaboration between nonprofits and business. Nonprofit and Voluntary Sector Quarterly. 2000; 29(suppl 1):69-97.

10. Buse K, Harmer AM. Seven habits of highly effective global public-private health partnerships: practice and potential. Soc Sci Med. 2007; 64(2):259-71. [PubMed: 17055633]

11. Kraak VI, Harrigan PB, Lawrence M, Harrison PJ, Jackson MA, Swinburn B. Balancing the benefits and risks of public-private partnerships to address the global double burden of malnutrition. Public Health Nutr 2011;FirstView. :1-15.

12. Kraak VI, Story M. A public health perspective on healthy lifestyles and public-private partnerships for global childhood obesity prevention. JADA. 2010; 110(2):192-200.

13. Kraak VI, Story M, Wartella EA, Ginter J. Industry progress to market a healthful diet to american children and adolescents. Am J Prev Med. 2011; 41(3):322-333. [PubMed: 21855748]

14. Healthy Weight Commitment Foundation. Healthy Weight Commitment Foundation, Fact Sheet. Washington DC: 2012.

15. Healthy Weight Commitment Foundation. Food and Beverage Manufacturers Pledging to Reduce Annual Calories By 1.5 Trillion By 2015. Press Release 2010; May 17, 2010. www.healthyweightcommit.org/news/Reduce_Annual_Calories/

16. Gortmaker SL, Swinburn BA, Levy D, et al. Changing the future of obesity: science, policy, and action. Lancet. 2011; 378(9793):838-47. [PubMed: 21872752]

17. Hall KD, Sacks G, Chandramohan D, et al. Quantification of the effect of energy imbalance on bodyweight. Lancet. 2011; 378(9793):826-37. [PubMed: 21872751]

18. Wang C, Orleans T, Gortmaker SL. Reaching the healthy people goals for reducing childhood obesity: closing the energy gap. Am J Prev Med. 2012; 42(5):437-44. [PubMed: 22516482]

19. Ng SW, Popkin BM. monitoring foods and nutrients sold and consumed in the U.S.: Dynamics and challenges. J Acad Nutr Diet (formerly J Am Diet Assoc). 2012; 112(1):41-45.e4.

20. HWCF Marketplace Evaluation Advisory Committee. www.cpc.unc.edu/projects/nutrans/policy/ food-industry-eval/eac-members-and-program-advisors

21. The Nielsen Company. ScanTrack. th.nielsen.com/products/rms_market.shtml

22. Zhen C, Taylor JL, Muth MK, Leibtag E. Understanding differences in self-reported expenditures between household scanner data and diary survey data: A comparison of Homescan and Consumer Expenditure Survey. Rev Agr Econ. 2009; 31(3):470-92.

23. Einav, L.; Leibtag, E.; Nevo, A. On the accuracy of Nielsen Homescan Data. Washington, DC: U.S. Department of Agriculture; 2008 Dec.

24. Einav L, Leibtag E, Nevo A. Recording discrepancies in Nielsen Homescan data: Are they present and do they matter? Quant Marketing Econ. 2010; 8(2):207-39.

25. National Archives and Records Administration. 21 CFR 101.9. Washington, DC: 1993.

26. NCHS, CDC, DHHS. National Health and Nutrition Examination Survey Data 2007-2008. www.cdc.gov/nchs/nhanes/nhanes2007-2008/nhanes07_08.htm

27. U.S. Department of Agriculture, ARS. USDA National Nutrient Database for Standard Reference. Nutrient Data Laboratory Home Page. 2010. www.ars.usda.gov/ba/bhnrc/ndl 
28. U.S. Department of Agriculture. Food and Nutrient Database for Dietary Studies, 4.1. 2010. www.ars.usda.gov/Services/docs.htm?docid=20511

29. Sharma LL, Teret SP, Brownell KD. The food industry and self-regulation: Standards to promote success and to avoid public health failures. Am J Public Health. 2010; 100(2):240-6. [PubMed: 20019306]

30. Brownell KD, Warner KE. The perils of ignoring history: Big Tobacco played dirty and millions died. How similar is Big Food? Milbank Q. 2009; 87(1):259-94. [PubMed: 19298423]

31. Koplan JP, Liverman CT, Kraak VI. Preventing childhood obesity: Health in the balance: Executive summary. JADA. 2005; 105(1):131-8.

32. Brownell KD, Koplan JP. Front-of-package nutrition labeling - an abuse of trust by the food industry? New Engl J Med. 2011; 364(25):2373-5. [PubMed: 21696305]

33. Koplan JP, Brownell KD. Response of the food and beverage industry to the obesity threat. JAMA. 2010; 304(13):1487-8. [PubMed: 20924016]

34. Ludwig DS, Nestle M. Can the food industry play a constructive role in the obesity epidemic? JAMA. 2008; 300(15):1808-11. [PubMed: 18854543]

35. Tooze JA, Kipnis V, Buckman DW, et al. A mixed-effects model approach for estimating the distribution of usual intake of nutrients: the NCI method. Stat Med. 29(27):2857-68. [PubMed: 20862656]

36. U.S. Department of Agriculture. USDA Table of Nutrient Retention Factors, Release 6. 2007. www.nal.usda.gov/fnic/foodcomp/Data/retn6/retn06.pdf

37. Hall KD, Guo J, Dore M, Chow CC. The progressive increase of food waste in America and its environmental impact. PLoS One. 2009; 4(11):e7940. [PubMed: 19946359] 


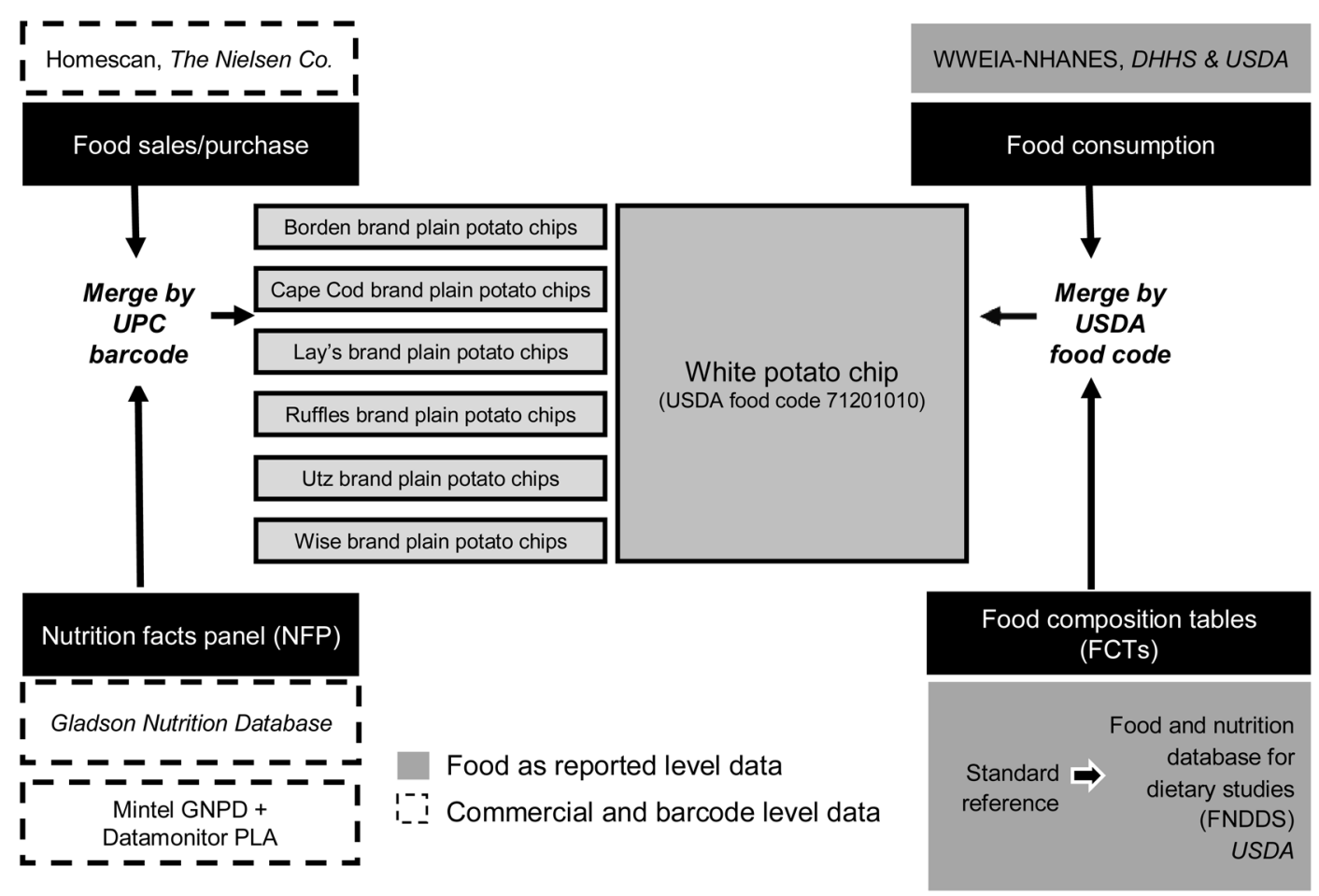

Figure 1.

Example of "crosswalk" between public and commercial data sources

FNDDS, Food and Nutrition Database for Dietary Studies; GNPD, Global New Product Database; PLA, product launch analytics; UPC, universal product code; USDA, U.S. Department of Agriculture; WWEIA NHANES, What We Eat in America dietary intake survey portion of the National Health and Nutrition Examination Survey 


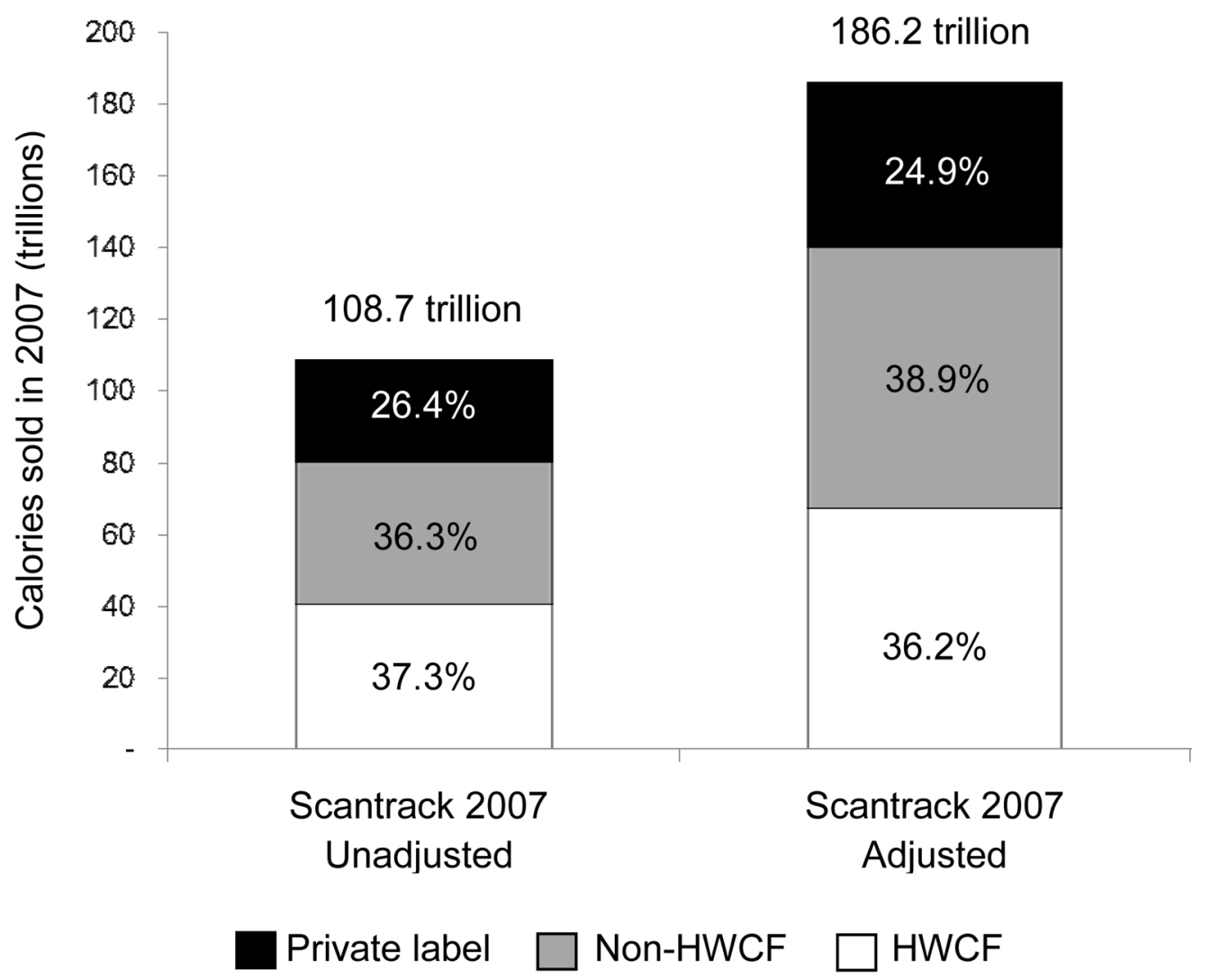

Figure 2.

Scantrack 2007 total annual calories sold (in trillions), unadjusted and adjusted HWCF, Healthy Weight Commitment Foundation 
Table 1

Homescan 2007 average daily calories from consumer packaged goods among children aged 2-18 years

\begin{tabular}{lc}
\hline Ages 2-18 years & $\mathbf{1 1 1 9}(\mathbf{1 . 9})$ \\
\hline Brands & $432(0.8)$ \\
HWCF & $347(0.6)$ \\
Non-HWCF & $341(0.5)$ \\
Private-labels/store & \\
Age (years) & $951(1.9)$ \\
$2-5$ & $1032(1.9)$ \\
$6-11$ & $1300(1.9)$ \\
$12-18$ & \\
Ethnicity & $1150(2.0)$ \\
Hispanic & $1148(2.0)$ \\
Non-Hispanic African American & $1167(2.1)$ \\
Non-Hispanic white & $1155(2.1)$ \\
Other & \\
Income level, \% of poverty threshold & $1112(1.9)$ \\
$<131$ & $1110(1.9)$ \\
$131-185$ & $1103(1.8)$ \\
> 185 & 16,692 households with 29,983 children aged 2-18 years \\
Sample size & \\
\hline
\end{tabular}

Note: Values are in kcals/day.

Data (M [SE]) are grouped by subpopulations weighted to be nationally representative. 


\section{Table 2}

NHANES What We Eat in America 2007/2008 average daily calories reported as consumed by children aged 2-18 years from stores and vending machines only

\begin{tabular}{lr}
\hline Characteristics & M (SE) \\
\hline Age (years) & $1275(17.8)$ \\
$2-18$ & $1194(17.3)$ \\
\hline $2-5$ & $1283(27.5)$ \\
$6-11$ & $1313(26.1)$ \\
$12-18$ & $1321(23.1)$ \\
Ethnicity & \\
Hispanic & $1200(42.8)$ \\
Non-Hispanic African American & $1305(29.8)$ \\
Non-Hispanic white & $1261(60.1)$ \\
Other & $1307(28.4)$ \\
Income, \% of poverty threshold & \\
$<131$ & $1288(41.2)$ \\
131-185 & $1254(23.6)$ \\
$>185$ & 2966 \\
Sample size & FNDDS 4.1 \\
Nutrition database(s) used & \\
\hline
\end{tabular}

Note: Values are in kcals/day.

FNDDS, Food and Nutrition Database for Dietary Studies; NHANES, National Health and Nutrition Examination Survey 


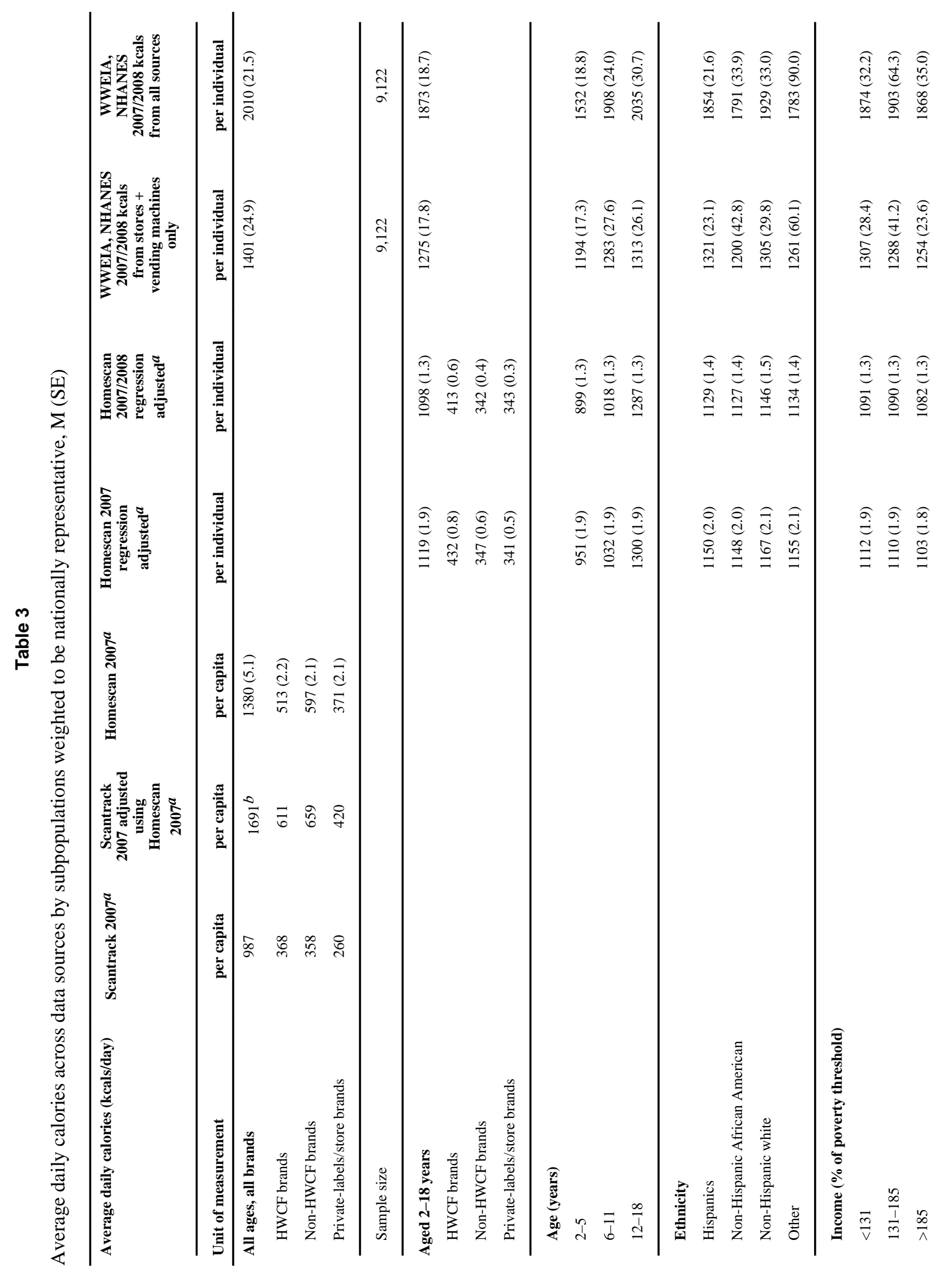




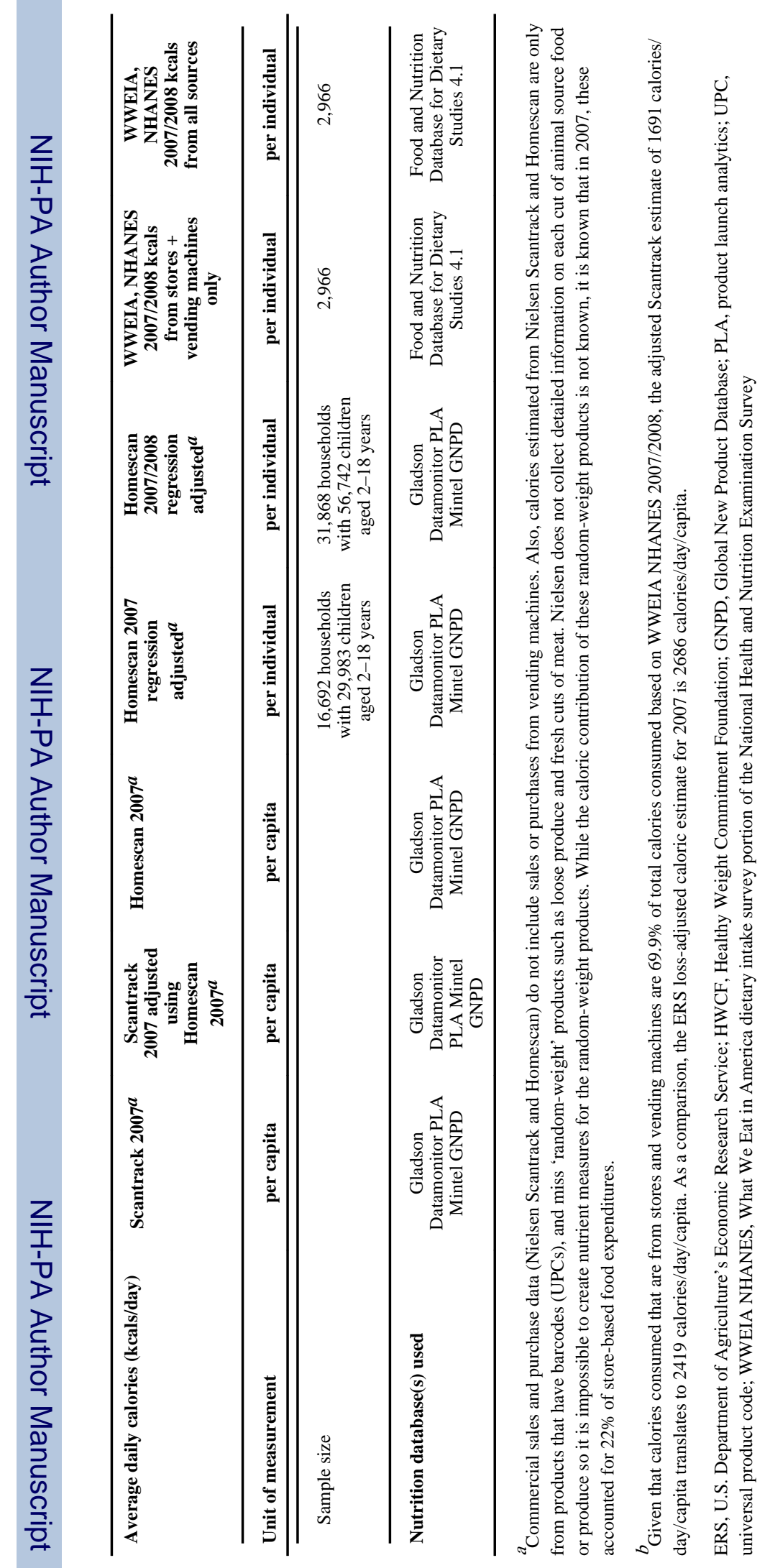

Am J Prev Med. Author manuscript; available in PMC 2014 February 01. 